\title{
Observational evidence for the plausible linkage of Equatorial Electrojet (EEJ) electric field variations with the post sunset F-region electrodynamics
}

\author{
V. Sreeja, C. V. Devasia, Sudha Ravindran, and Tarun Kumar Pant \\ Space Physics Laboratory, Vikram Sarabhai Space Centre, Trivandrum 695022, India
}

Received: 3 April 2009 - Revised: 12 October 2009 - Accepted: 30 October 2009 - Published: 10 November 2009

\begin{abstract}
The paper is based on a detailed observational study of the Equatorial Spread F (ESF) events on geomagnetically quiet $\left(A_{p} \leq 20\right)$ days of the solar maximum (2001), moderate (2004) and minimum (2006) years using the ionograms and magnetograms from the magnetic equatorial location of Trivandrum $\left(8.5^{\circ} \mathrm{N} ; 77^{\circ} \mathrm{E}\right.$; dip lat $\left.\sim 0.5^{\circ} \mathrm{N}\right)$ in India. The study brings out some interesting aspects of the daytime Equatorial Electrojet (EEJ) related electric field variations and the post sunset F-region electrodynamics governing the nature of seasonal characteristics of the ESF phenomena during these years. The observed results seem to indicate a plausible linkage of daytime EEJ related electric field variations with pre-reversal enhancement which in turn is related to the occurrence of ESF. These electric field variations are shown to be better represented through a parameter, termed as "E", in the context of possible coupling between the Eand F-regions of the ionosphere. The observed similarities in the gross features of the variations in the parameter "E" and the F-region vertical drift $\left(V_{z}\right)$ point towards the potential usage of the EEJ related parameter "E" as an useful index for the assessment of $V_{z}$ prior to the occurrence of ESF.
\end{abstract}

Keywords. Ionosphere (Electric fields and currents; Equatorial ionosphere; Ionospheric irregularities)

\section{Introduction}

The electrodynamics of the equatorial ionospheric E- and Fregions is essentially controlled by the electric fields generated by the movement of the electrically conducting upper atmosphere across the Earth's magnetic field through neutral wind forcings. Major phenomena of the equatorial ionosphere are mostly associated with the generation of

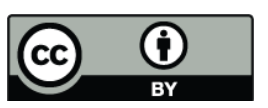

Correspondence to: V. Sreeja

(v.sreeja@gmail.com)
Equatorial Electrojet (EEJ), which is a narrow band of enhanced eastward current flowing in the 100-120 km altitude region i.e. E-region within $\pm 3^{\circ}$ latitude of the dip equator in the morning, and the subsequent development of the Equatorial Ionization Anomaly (EIA), also known as Appleton Anomaly, in the F-region.

After sunrise with the build up of the EEJ, the east-west component of its electric field $\boldsymbol{E}$ (which has its origin in the global dynamo field) gets mapped to the F-region altitudes along the highly conducting geomagnetic field lines. In the F-region, the electric field $\boldsymbol{E}$ causes the vertical $\boldsymbol{E} \times \boldsymbol{B}$ plasma drift through the interaction with the north-south component of the Earth's magnetic field $(\boldsymbol{B})$ and causes the development of EIA. The EEJ grows in strength reaching a maximum around local noon followed by its gradual decay to a low value at around sunset, as indicated by the EEJ induced ground magnetic field $(\boldsymbol{B})$ variations.

The F-region plasma that is uplifted over the dip equator, by the process of the vertical $\boldsymbol{E} \times \boldsymbol{B}$ plasma drift (also called the plasma fountain process), diffuses along the Earth's magnetic field lines resulting in depletion (accumulation) of plasma around the dip equator (away from the equator) producing a double humped latitudinal distribution, known as EIA, on either side of the magnetic equator at $\pm 15-20^{\circ}$ dip latitude. The EIA forms generally at around 09:00 LT with the crests close to the dip equator to start with, and gains in strength (with both poleward movement and intensification of crests) in the afternoon period (Sastri, 1990). A one-toone correlation between the strength of the EIA and the time integrated strength of the EEJ has been observed, confirming that the driving force for both the EIA and the EEJ is the same (Dunford, 1967; Rastogi and Rajaram, 1971; Rush and Richmond, 1973; Raghavarao et al., 1978).

Extensive information on equatorial F-region plasma drifts and their dependence on season and solar activity is available (Sastri, 1995; Maynard et al., 1995, and the references therein). Fejer (1991) and Scherliess and Fejer (1999) have

Published by Copernicus Publications on behalf of the European Geosciences Union. 
discussed the large day-to-day variability in the F-region vertical drift velocities as measured by the Jicamarca Incoherent Scatter radar. Anderson et al. (2002) established a quantitative relationship between the vertical $\boldsymbol{E} \times \boldsymbol{B}$ drift velocity in the ionospheric F-region and the daytime strength of the EEJ in the South American (west coast) longitude sector.

It is well known that the F-region plasma drift reverses from upward to downward after sunset. However, just before the reversal, there is a clear cut post sunset enhancement in the vertical $\boldsymbol{E} \times \boldsymbol{B}$ drift associated with the activation of the F-region dynamo in the evening hours (Rishbeth, 1981; Eccles, 1998). This is called the post sunset or the pre-reversal enhancement (PRE) of the F-region zonal electric field. The PRE is basically responsible for the large uplift of the F-layer and the evening time resurgence of the EIA. The exact mechanism for the post sunset F-layer uplift i.e. whether it is due to the F-region dynamo electric fields getting freed from the field line E-region loading effect (Farley et al., 1986) or due to the irrotational nature of the electric field at the sunset terminator manifesting itself as an enhanced zonal wind (Rishbeth, 1981) or due to the evening EEJ (Haerendel and Eccles, 1992) is still not fully understood. Recently, Kelley et al. (2009) considered the above three competing mechanisms that exist for the PRE, in the light of the penetration of a large electric field of interplanetary origin. Their study suggests that the normal PRE must be created by the Haerendel and Eccles (1992) mechanism, in which the EEJ partially closes in the post sunset F-region, and that the other two mechanisms are secondary. However, whatever be the mechanism, the fact is that during the sunset hours, the F-region is uplifted to higher altitudes due to the enhanced zonal electric field, the magnitude of which exhibits large day-to-day variability. At higher altitudes, conditions are conducive for the triggering of the plasma instability responsible for Equatorial Spread F (ESF)/plasma bubble irregularity events in the nighttime F-region.

The plasma irregularities in the nighttime equatorial Fregion manifest in the form of diffuse echoes in the ionograms and are known as ESF. By a careful analysis of ground based ionospheric data, a close linkage between EIA and ESF was shown by Raghavarao et al. (1988), Alex et al. (1989) and Jayachandran et al. (1997). The basic mechanism responsible for the generation of ESF is the Collisional Rayleigh-Taylor (CRT) plasma instability. After local sunset, the base of the F-region gets lifted up because of two factors (i) the recombination of molecular ions in the lower F-region and (ii) the electrodynamical lifting of the F-region (Rishbeth, 1981; Eccles, 1998). The lifting of the F-region to $300 \mathrm{~km}$ and beyond is generally considered to be a necessary condition for the triggering of R-T instability, though may not be sufficient (Rishbeth, 1981). The PRE has a strong control on the height rise of the evening equatorial $\mathrm{F}$ layer by generating steep vertical gradients in the electron density profile and as a consequence on the occurrence of ESF. Fejer et al. (1999) have studied the effects of $V_{z}$ on the genera- tion and evolution of ESF, while Hysell (2000) has given an overview of plasma irregularities causing ESF.

The occurrence of ESF varies from day-to-day with season, geographical location and also with solar and geomagnetic activity. These aspects of ESF have been studied extensively over the past several years (Chandra and Rastogi, 1970; Woodman and LaHoz, 1976; Fejer and Kelley, 1980; Maruyama and Matuura, 1984; Aarons, 1993; Hysell and Burcham, 2002, and the references therein). Maruyama (1988) studied the effects of the meridional winds and showed that a poleward wind would inhibit ESF by pushing the ionization along the field lines to the E-region. The increased conductivity in the E-region would oppose the upliftment of the base of the F-region to greater heights by loading the F-region dynamo. However, the polarity (equatorward/poleward) and magnitude of the meridional winds have been shown to play a significant role only when the maximum bottom height of the post sunset F-layer $\left(h^{\prime} F\right)$ is below a critical height. Above the critical height, the polarity of the winds was shown to be not having a direct control on the generation of ESF (Devasia et al., 2002).

While the aspect of the seasonal variation of ESF is reasonably understood (Abdu et al., 2000), the day-to-day and shorter term variabilities are not adequately understood because of a lack of knowledge on the interdependent variabilities of the ambient $\mathrm{E}$ - and F-region parameters that control the ESF development. The presence of ESF irregularities can cause scintillations in VHF, UHF and even the microwave frequency range. These scintillations produce disruptions of the communication and navigation links using satellites. Hence, understanding the variability of ESF occurrence and forecasting of this phenomenon are of practical importance. It is the background electrodynamic and neutral dynamic conditions that basically dictate the occurrence/non-occurrence of ESF on a particular day. Earlier studies have tried to make an attempt to forecast the occurrence of ESF (Raghavarao et al., 1988; Sridharan et al., 1994; Mendillo et al., 2001; Thampi et al., 2006, and the references therein). These studies imply that the background ionospheric and thermospheric conditions during the daytime play a very crucial role in the generation of ESF.

The purpose of the present paper is to provide an observational evidence based on a statistical study for the plausible control or linkage of the maximum rate of morning electric field build up in the EEJ with the occurrence of ESF during different seasons under maximum, moderate and minimum solar activity conditions. In this process, the post sunset F-region characteristics preceding the ESF occurrences on magnetically quiet days vis-à-vis the variabilities in the EEJ electric field during this period are examined. The three years chosen for the present study have distinctly different patterns of ESF occurrence during the different seasons to examine the above aspect in detail. 


\section{Data and methodology of analysis}

The study is based on the analysis of ionograms and magnetograms obtained at the magnetic equatorial location of Trivandrum $\left(8.5^{\circ} \mathrm{N} ; 77^{\circ} \mathrm{E}\right.$; dip lat $\left.\sim 0.5^{\circ} \mathrm{N}\right)$ in India during the solar maximum year of 2001 , moderate activity year of 2004 and the minimum year of 2006. Information about the F-region parameters like $f o \mathrm{~F} 2$ (critical frequency of the F-layer) and $h^{\prime} F$ have been obtained from the quarter hourly ionograms available during all the magnetically quiet $\left(A_{p} \leq 20\right)$ days of these years. We have adopted the commonly used method of using the information on the evening time $h^{\prime} F$ variations to compute $d h^{\prime} F / d t$ or equivalently the $\boldsymbol{E} \times \boldsymbol{B}$ drift for obtaining the PRE. The vertical drift velocity $V_{z}$ (PRE) of the layer as given by, $V_{z}=\left[d\left(h^{\prime} F\right) / d t\right]$, should be close to the real F-region vertical plasma drifts for layer heights $\geq 300 \mathrm{~km}$ (Bittencourt and Abdu, 1981; Batista et al., 1986), which usually is the case during evening hours for the solar maximum year. The F-region height rise due to chemical losses is of the order of $5 \mathrm{~m} / \mathrm{s}$ and is negligible when compared to large vertical drift velocities due to the PRE in the zonal electric field (Krishna Murthy et al., 1990; Basu et al., 1996). Another method for deriving the F-region drift has been evolved by using the information on the $\mathrm{hmF} 2$ values obtained from the electron density profile (Liu et al., 2004, and the references therein).

Since $\boldsymbol{E} \times \boldsymbol{B}$ drift velocity generally reaches its maximum before the onset of ESF (Fejer et al., 1999; Whalen, 2002), the maximum $\boldsymbol{E} \times \boldsymbol{B}$ drift velocity $\left(V_{z}\right)$ and its occurrence time during the post sunset hours have also been used as important parameters in relation to the ESF onset time on each day. The time of the maximum $V_{z}$ can be treated as the reversal time of the upward $\boldsymbol{E} \times \boldsymbol{B}$ drift.

Hourly values of the Earth's magnetic field $(\Delta H)$ at Trivandrum and at Alibag $\left(18.7^{\circ} \mathrm{N} ; 73^{\circ} \mathrm{E}\right.$; dip lat $\left.\sim 13^{\circ} \mathrm{N}\right)$, a location outside the electrojet region, published by Indian Institute of Geomagnetism (IIG), Mumbai (India) is used to characterize the strength of EEJ on each day as given by the relationship, $\left(\Delta H_{\mathrm{TIR}}-\Delta H_{\mathrm{ABG}}\right)$. However, Devasia et al. (2006) have shown that the hourly values of $(\Delta H)$ at Trivandrum $\left(\Delta H_{\mathrm{TIR}}\right)$ denotes the intensity/strength of EEJ over the magnetic equatorial location of Trivandrum and that the time variations of $\left(\Delta H_{\mathrm{TIR}}\right)$ i.e. $\left.\left\{d \Delta H_{\mathrm{TIR}}\right) / d t\right\}$ during daytime is a proxy parameter for indicating the variations in the east-west electric field in EEJ. The maximum gradient of $\left.\left\{d \Delta H_{\mathrm{TIR}}\right) / d t\right\}$ denoted as $\left.\left\{\left(d \Delta H_{\mathrm{TIR}}\right) / d t\right)_{\max }\right\}$ in the morning hours is assumed to give an indirect estimate of the maximum build up rate of the EEJ electric field. The above parameters thus obtained on each of the ESF days have been used to examine the relationship/correspondence, if any, between the EEJ related variability and the occurrence of ESF through the inter-dependence between the development of EIA, strength and occurrence time of $V_{z}$.

\section{Results and discussion}

\subsection{Nature of variation of $E$ - and F-region parameters: growth and decay rates of the daytime EEJ strength}

Figure $1 \mathrm{a}$ and $\mathrm{b}$ shows the temporal variations of the relevant E- and F-region parameters on a typical ESF (15 March 2001) and a non-ESF day (4 March 2001) during the period under study. The bottom panels of Fig. 1a and $\mathrm{b}$ give the daytime variations of $\Delta H$ over Trivandrum on the ESF day and the non-ESF day respectively. The second panel from bottom shows the time variations of $d\left(\Delta H_{\mathrm{TIR}}\right) / d t$ and $\left\{d\left(\Delta H_{\mathrm{TIR}}-\right.\right.$ $\left.\left.\Delta H_{\mathrm{ABG}}\right) / d t\right\}$. The variations of both $\left\{d\left(\Delta H_{\mathrm{TIR}}\right) / d t\right\}$ and $\left\{d\left(\Delta H_{\mathrm{TIR}}-\Delta H_{\mathrm{ABG}}\right) / d t\right\}$ are "quite similar", except for a small constant difference in their magnitudes. The third panel from bottom represents the variations in the $N m \mathrm{~F} 2$ or equivalently in $[f o \mathrm{~F} 2]^{2}$ \{proportional to the electron number density $(\mathrm{N})$ corresponding to $f o \mathrm{~F} 2\}$.

The temporal variations of $d\left(\Delta H_{\mathrm{TIR}}\right) / d t$ and $N m \mathrm{~F} 2$ show distinctly different pattern on the ESF and the non-ESF days, with considerable difference in the maximum values of $d\left(\Delta H_{\mathrm{TIR}}\right) / d t$ in the morning and afternoon hours. The maximum values of $\left\{d\left(\Delta H_{\mathrm{TIR}}\right) / d t\right\}$ in the morning (i.e. usually around 09:30-10:30 IST) and afternoon hours (i.e. around 14:30-15:30 IST) gives respectively the maximum values of the growth and decay rates of the EEJ electric field. Their amplitudes (maximum values) as well as their time of occurrence show variability on a day-to-day, monthly, seasonal as well as on solar activity level basis.

Other parameters of interest in the post sunset F-region are the variations in $V_{z}$ and $h^{\prime} F$ which are shown in the top panels of Fig. 1a and b. The presence of large value for $V_{z}$ and $h^{\prime} F$ in the post sunset hours preceding the ESF occurrence is the most important characteristic feature observed on the ESF day in comparison to the non-ESF day. The nature of variability of the maximum value of $\left\{d\left(\Delta H_{\mathrm{TIR}}\right) / d t\right\}$ is observed to have some sort of an association with the ESF occurrence. The present study is an attempt to investigate their plausible linkage with the post sunset F-region behaviour during different seasons under the different solar activity conditions.

Figure $2 \mathrm{a}-\mathrm{c}$ shows the day-to-day and monthly variations in the morning (bottom panel) and afternoon (top panel) maximum gradient of $\Delta H$ [maximum values of $d(\Delta H) / d t)$ ] on all the magnetically quiet days $\left(A_{p} \leq 20\right)$ for the three years. The monthly mean variation obtained from the individual values is represented by the thick continuous curve in Fig. 2a for 2001, Fig. 2b for 2004 and Fig. 2c for 2006. It is clear from the figures that except for the difference in the amplitudes, the mean variations in the morning gradient of $\Delta H$ (bottom panel) are very regular and well defined with typical equinoctial (March-April and September-October months) maxima and solstitial (June-July and November-December months) minima during the three years. Whereas, in the case of the afternoon gradient (top panel), the variation pattern 

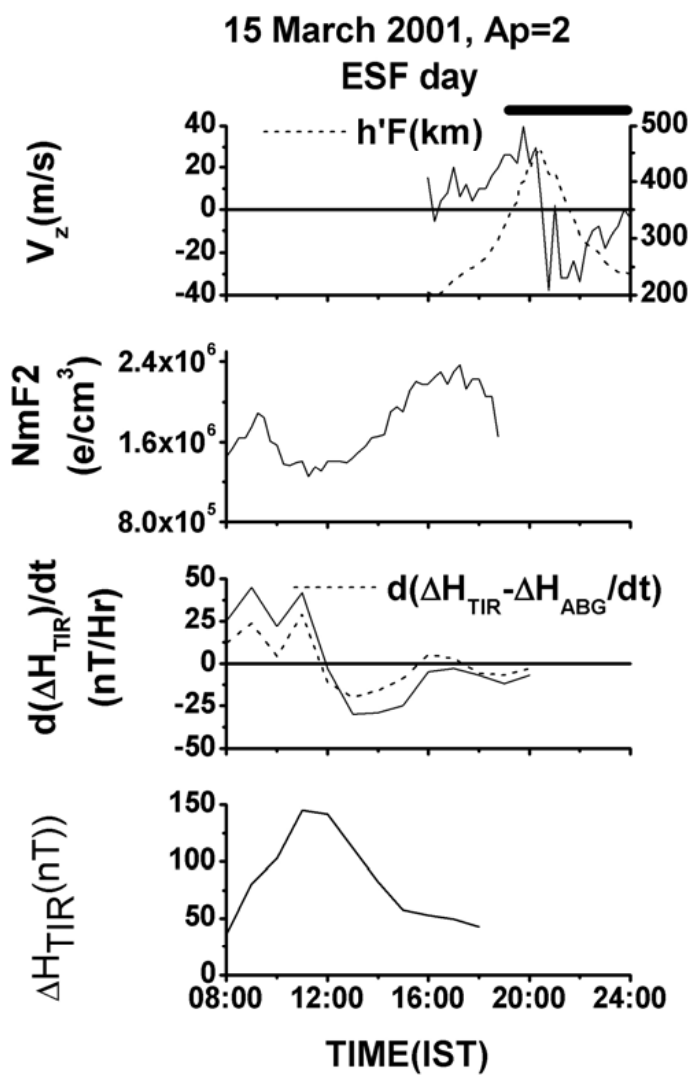

Fig. 1a. Variations in $\Delta H_{\mathrm{TIR}}$ (bottom panel) along with the variations in $\left\{d\left(\Delta H_{\mathrm{TIR}}\right) / d t\right\}$ and $\left\{d\left(\Delta H_{\mathrm{ABG}}-\Delta H_{\mathrm{TIR}}\right) / d t\right\}$ (second panel), $N m \mathrm{~F} 2=1.24 \mathrm{e} 4\left(f_{o} \mathrm{~F} 2\right)^{2}$ (third panel) and $V_{z}$ and $h^{\prime} F$ along with the duration of ESF (top panel) on a typical ESF day of 15 March 2001.

(both day-to-day and monthly) is more or less random in nature. The random nature of variations for the afternoon gradient during the three years does not seem to have any similarity what so ever with the systematic seasonal variations manifested by the morning gradients. We have defined the morning maximum gradient in $\Delta H$ as the parameter "E".

\subsection{The rational of taking the parameter "E", denoted} by $\left.\left\{d \Delta H_{\mathrm{TIR}}\right) / d t\right\}_{\max }$ in the morning hours

As is understood today, the upward propagating tides are basically responsible for shaping the major phenomena of the equatorial dynamo region (Abdu et al., 2006). Therefore, the day-to-day variability as seen in the EEJ could be ascribed also to the variability in the tidal structure, which also exhibits large seasonal variability. The most prominent manifestations of this day-to-day variability of EEJ are the time at which the EEJ peaks and it's strength. Evidences are there that the gravity and planetary waves, which are also of lower atmospheric origin, may interact with the tides causing significant variations in their amplitude and phase. In this context, the EEJ variability at any given time can have two con-
04 March 2001, Ap=19 NESF day
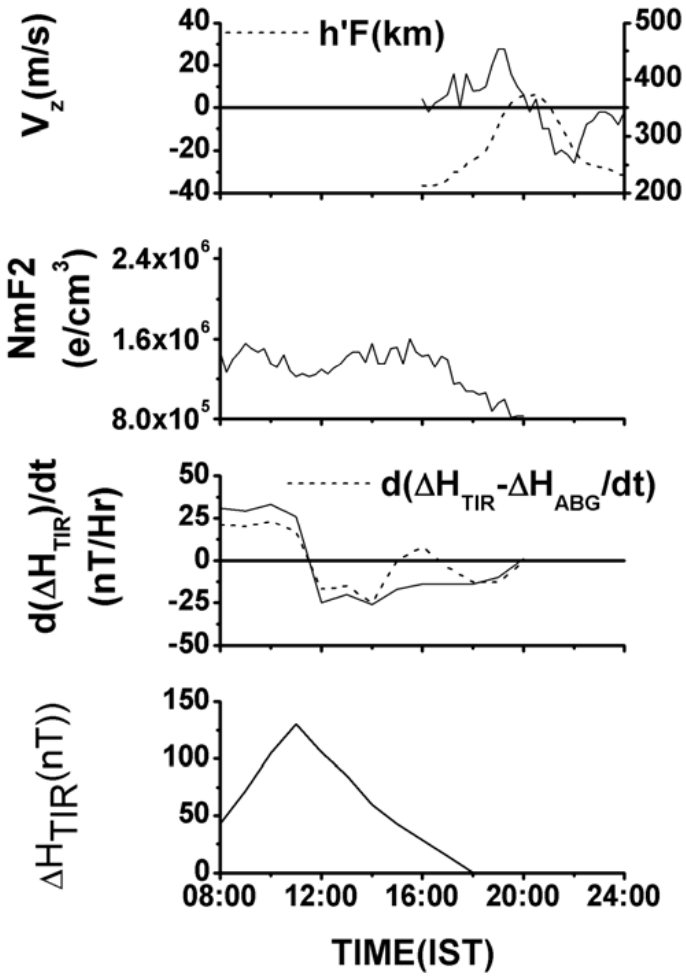

Fig. 1b. Same as in Fig. 1a but on a non-ESF day of 4 March 2001.

tributions, one from the insitu modulations in the ionosphere and the other from changes in the forcing from the lower atmosphere. In this context, it is conjectured that though it has been shown that the integrated EEJ strength has a positive correlation with some of the F-region characteristics, e.g. pre-reversal drift of F-region, the main influence of the E-region field on the F-region comes at a time when this field is fast developing and approaching maximum. For instance, the EIA, which characterizes the ionization distribution over the low and equatorial latitudes on any given day, is already well developed around the time the EEJ exhibits the noontime maximum, though it continues to evolve even after that.

\subsection{Monthly variations in the occurrence frequency of ESF}

Table 1 gives a statistics of the monthly occurrence of ESF and non-ESF days along with the percentage occurrence of ESF during each month of 2001, 2004 and 2006 using available ionogram data of the magnetically quiet days of every month. The percentage occurrence for each month is taken as the percentage number of days on which at least one premidnight ESF event is observed out of the total number of magnetically quiet days of that particular month. 
(a)

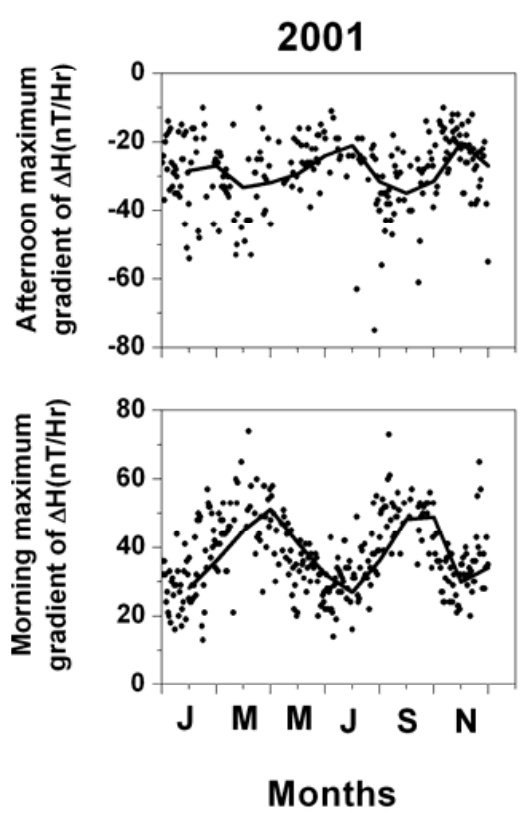

(b)
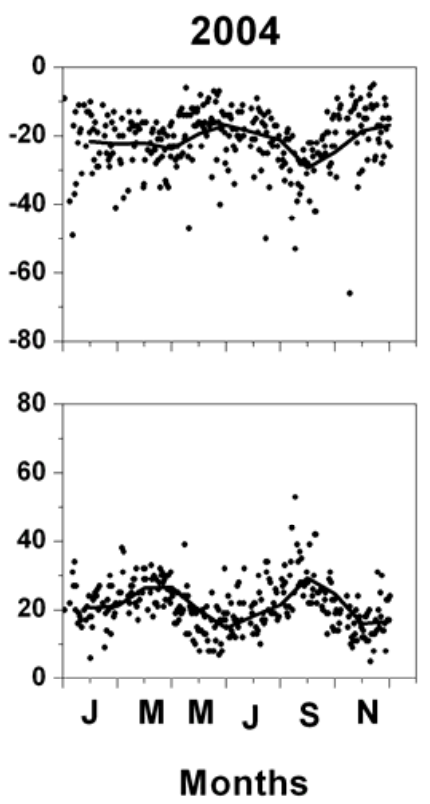

(c)
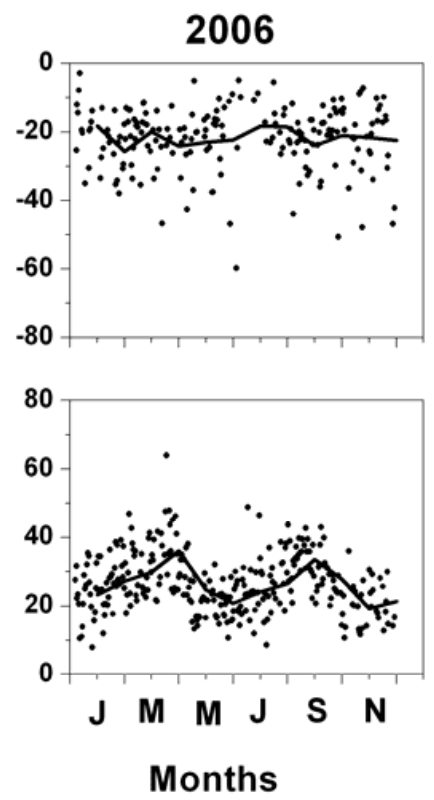

Fig. 2. (a) Daily variations in the morning maximum and afternoon maximum values of $d\left(\Delta H_{\mathrm{TIR}}\right) / d t$ on all the magnetically quiet days $\left(A_{p} \leq 20\right)$ for the solar maximum year of 2001. The monthly mean values of these parameters are shown by thick lines in the respective plots of the daily values. (b) Same as in panel (a), but for the moderate activity year of 2004. (c) Same as in panel (a), but for the solar minimum year of 2006.

The top panel of Fig. 3 shows the monthly variation in the percentage occurrence of ESF for the three years. Clearly a very high percentage occurrence (above $\sim 85 \%$ ) is observed in all the months during 2001, except in July where the value is slightly less $(\sim 75 \%)$. During 2004 , the highest percentage occurrence (above $\sim 65 \%$ ) is observed during the equinoctial months (March-April and September-October) and lowest $(\sim 4 \%)$ during the summer solstitial months of June-July. The percentage occurrence probability during the other months is between 30-50\%. During 2006, the highest percentage occurrence (above $\sim 60 \%$ ) is observed during the equinoctial months of March-April and October and also during the winter month of November. The lowest value of $\sim 8 \%$ is observed in the month of July. In June, however, the percentage occurrence probability is zero. In all the other months, the occurrence probability is between $30-50 \%$.

The bottom panel of Fig. 3 shows the 10 day mean variations of the parameter "E" on ESF days of each month. The middle panel of Fig. 3 shows an identical representation for $V_{z}$. A comparison between the percentage occurrence of ESF and the mean variations of the parameter " $E$ " and $V_{z}$ indicate a reasonably good correspondence between them.

\subsection{Possible cause for the linkage of the parameter " $E$ "' with $V_{z}$}

To investigate the possible cause and effect relationship between the parameter " $E$ " and $V_{z}$, we chose one international quiet day (on which ESF was observed) of each month for the year 2001 and calculated the parameter "E" on each of these days. Figure 4a shows the scatter plot of the parameter "E" versus $V_{z}$ for these days. Quite evidently, a fairly good positive correlation $(R=0.66)$ is observed between the two parameters. The possible relationship between parameter "E" and $V_{z}$ can be thought of as follows: a large value for the parameter " $E$ " means that the EIA is evolving at a faster rate or rather the strength of the EIA is getting enhanced. The intensification of EIA reduces the plasma density over the magnetic equator (trough of EIA) and simultaneously increases the plasma density over the crest regions. The decrease in the plasma density over the magnetic equator reduces the ion drag on the neutrals and hence the zonal wind is enhanced prior to sunset. The enhanced anomaly will also increase the F- to E-region flux tube integrated Pedersen conductivity (Crain et al., 1993). Both these changes in turn produce a large eastward electric field and hence causes a large post sunset vertical drift of the F-layer i.e. a larger value of the parameter " $E$ " in turn is related with a larger value of $V_{z}$.

Figure $4 \mathrm{~b}$ depicts the average $V_{z}$ (on the ESF days) along with their standard deviations against the parameter " $E$ " for 
Table 1. Variations in the monthly occurrence pattern of the ESF and the non-ESF days along with the ESF percentage occurrence probability during each month of the solar maximum year of 2001, moderate activity year of 2004 and the solar minimum year of 2006.

\begin{tabular}{|c|c|c|c|}
\hline Months & $\begin{array}{l}\text { No of ESF days } \\
\quad\left(A_{p} \leq 20\right)\end{array}$ & $\begin{array}{l}\text { No of NESF days } \\
\quad\left(A_{p} \leq 20\right)\end{array}$ & $\begin{array}{l}\text { ESF occurrence } \\
\text { probability }\end{array}$ \\
\hline \multicolumn{4}{|l|}{2001} \\
\hline January & 29 & 1 & 97 \\
\hline February & 22 & 1 & 96 \\
\hline March & 20 & 2 & 91 \\
\hline April & 13 & 1 & 93 \\
\hline May & 21 & 1 & 96 \\
\hline June & 15 & 1 & 94 \\
\hline July & 15 & 5 & 75 \\
\hline August & 20 & 3 & 87 \\
\hline September & 19 & 0 & 100 \\
\hline October & 12 & 0 & 100 \\
\hline November & 19 & 0 & 100 \\
\hline December & 20 & 3 & 87 \\
\hline \multicolumn{4}{|l|}{2004} \\
\hline January & 7 & 10 & 41 \\
\hline February & 6 & 15 & 29 \\
\hline March & 14 & 7 & 67 \\
\hline April & 17 & 5 & 77 \\
\hline May & 9 & 13 & 41 \\
\hline June & 2 & 26 & 7 \\
\hline July & 1 & 23 & 4 \\
\hline August & 7 & 18 & 28 \\
\hline September & 15 & 7 & 68 \\
\hline October & 18 & 10 & 64 \\
\hline November & 7 & 14 & 33 \\
\hline December & 7 & 18 & 28 \\
\hline \multicolumn{4}{|l|}{2006} \\
\hline January & 11 & 13 & 46 \\
\hline February & 7 & 21 & 25 \\
\hline March & 17 & 11 & 61 \\
\hline April & 18 & 8 & 69 \\
\hline May & 13 & 11 & 54 \\
\hline June & 0 & 25 & 0 \\
\hline July & 2 & 23 & 8 \\
\hline August & 4 & 22 & 15 \\
\hline September & 13 & 15 & 46 \\
\hline October & 14 & 9 & 61 \\
\hline November & 11 & 4 & 73 \\
\hline December & 2 & 10 & 17 \\
\hline
\end{tabular}

the years of 2001, 2004 and 2006 irrespective of the seasons. Discrete intervals of $5 \mathrm{nT} / \mathrm{h}$ for the parameter "E" have been used to study the response of $V_{z}$ to this parameter. It is clear from this figure that on an average, $\mathrm{V}_{z}$ exhibits a positive relationship with the parameter "E" during the solar maximum year of 2001 and the moderate activity year of 2004. But, for the solar minimum year of 2006, it is very difficult to deduce such a relation, as the number of ESF events itself was very low. The large error bars in the plot indicate that for a given parameter "E", there is a large scatter in the value of
$V_{z}$. This feature suggests that $V_{z}$ does not uniquely depend on the magnitude of parameter " $E$ ", though the trends appear to come out well.

\subsection{Monthly variations in the Maximum $E \times B$ drift $\left(V_{z}\right)$ corresponding to the observed variations of the parameter "E"}

Figure 5 is a gross statistical picture showing the monthly variability in the parameter "E" and maximum $V_{z}$ along with the time of maximum $V_{z}$ and the onset time of ESF for the period under study. As is clear from the figure, maximum $V_{z}$ values above $15 \mathrm{~m} / \mathrm{s}$ are characteristic of all the months of 2001, with peak values of $V_{z}$ more than $35 \mathrm{~m} / \mathrm{s}$ in the equinoctial and the winter solstitial months, where the ESF occurrence probability is also more than $90 \%$. The time of occurrence of maximum $V_{z}$ is observed to be centered around 19:00 IST or earlier during almost all the months of 2001. The fairly larger occurrence probability of ESF even during the winter solstitial months can also be explained on the basis of the larger $V_{z}$ values and the earlier occurrence time of $\mathrm{V}_{z}$ during these months. Another interesting relationship (shown in the top panel of the Fig. 5) observed during 2001 is between the average onset time of ESF and $V_{z}$, which indicate that the earlier onset time of ESF during the equinoctial months are associated with the larger values of $V_{z}$. This feature is also manifested, though less clearly, during the moderate activity year of 2004 and the solar minimum year of 2006, in association with the ESF events of the equinoctial months. The onset time of ESF during the different months of 2004 is between 19:00 and 20:00 IST, whereas during 2006, the onset time is delayed upto about 20:00 IST. A comparatively lower value of $V_{z}$ and later occurrence time (beyond 19:00 IST) is also reflected in the ESF occurrence during 2004 and 2006. Of course these observed results conform to the already known fact that both the time of $V_{z}$ and the onset of ESF are basically controlled by the sunset time (Maruyama and Matuura, 1984).

These observations show that a large upward $V_{z}$ value and its early occurrence time in the post sunset hours are the most favourable conditions for the onset of ESF over Trivandrum. This is in contrast to the observation of a large $V_{z}$ and its late occurrence time in the post sunset hours as reported by Maruyama (1988) and Fejer et al. (1999) in the case of ESF occurrence over Jicamarca during the summer months. Over the Indian region, Vyas and Chandra (1991) reported that a delayed afternoon zonal F-region drift reversal was associated with ESF occurrence.

It is also clear from the Fig. 5 that, the larger $V_{z}$ values observed during the equinoctial months (March, April, September and October) of 2001 are associated with the highest percentage occurrence of ESF ( $>90 \%$ ) during these months (Fig. 3). This is because the larger $V_{z}$ lifts the F-layer to higher altitudes where the background ionospheric/thermospheric conditions are more favorable for the 

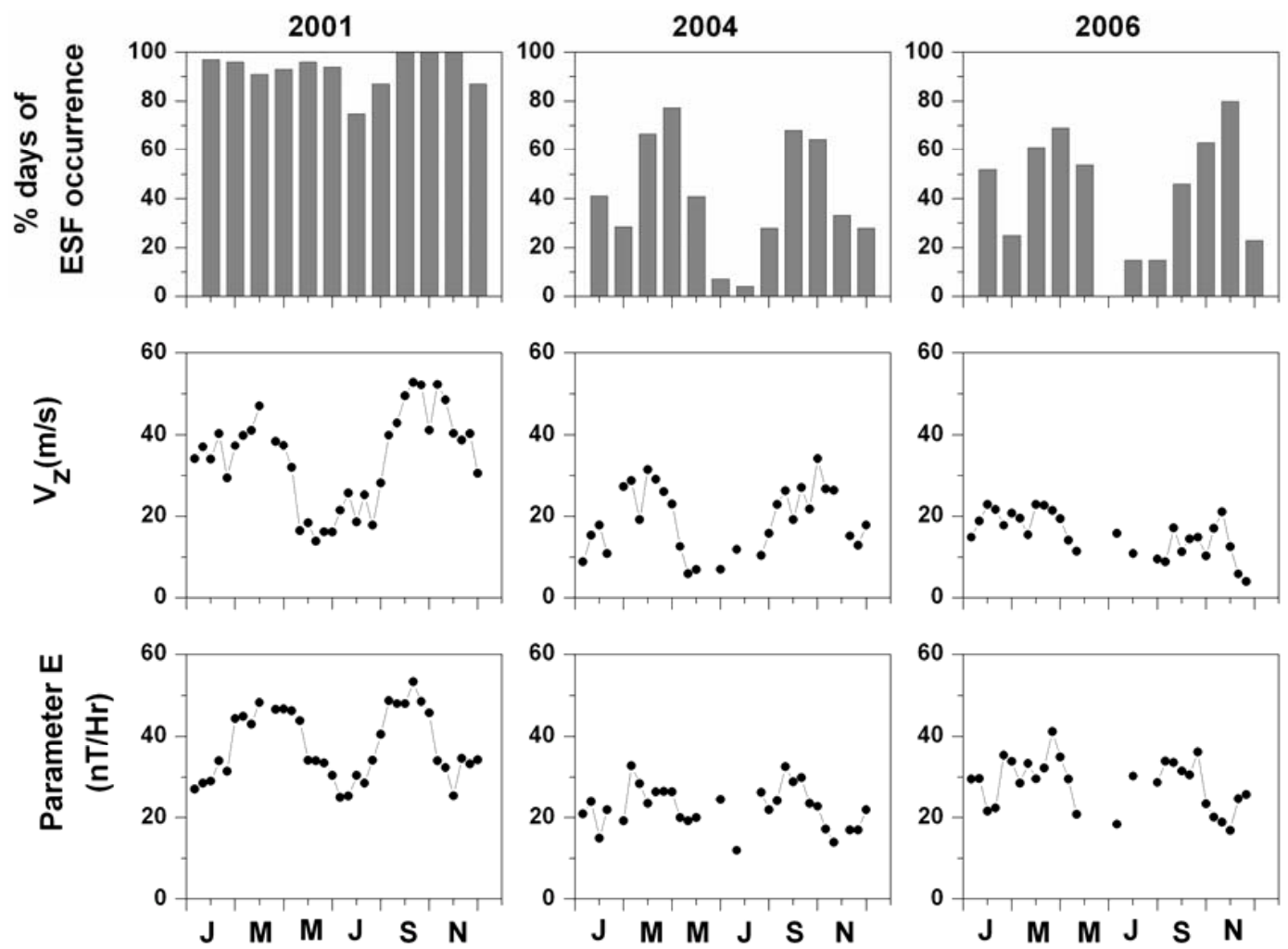

Months

Months

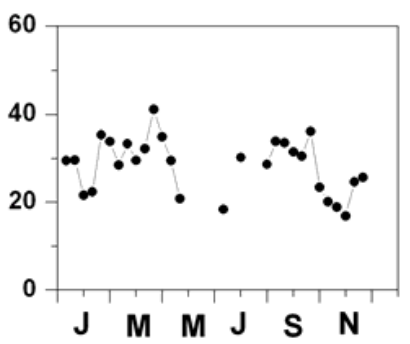

Months

Fig. 3. The percentage of days of ESF occurrence on all the magnetically quiet days $\left(A_{p} \leq 20\right)$ of each month of 2001,2004 and 2006 (top panel). The middle panel shows the 10 day mean variations in the $V_{z}$ values on ESF days of the month. The bottom panel shows an identical representation for the "parameter E".

growth rate of the R-T instability causing ESF. In contrast, the comparatively lower values of $V_{z}$ observed during the summer solstitial months of May, June, July and August could not lead to the uplifting of the F-layer to the higher altitudes. Thus, the percentage occurrence of ESF is also comparatively lower during these months, but still much larger than that observed during the equinoctial months of the solar minimum year, where the $V_{z}$ values are comparatively lower. The observed inter-dependence between the different parameters thus seem to be useful in arriving at a gross representative estimate of the parameter "E", which would be a fairly good statistical estimate of the PRE that assists the R$\mathrm{T}$ instability growth, which is very much in accordance with earlier results (Sultan, 1996; Fejer et al., 1999; Kudeki et al., 1999; Whalen, 2002).

\section{Summary and conclusions}

The details of the observational results relating to the plausible linkage of the daytime EEJ related electric field variabilities with the occurrence of ESF under magnetically quiet conditions during different seasons of the solar maximum,

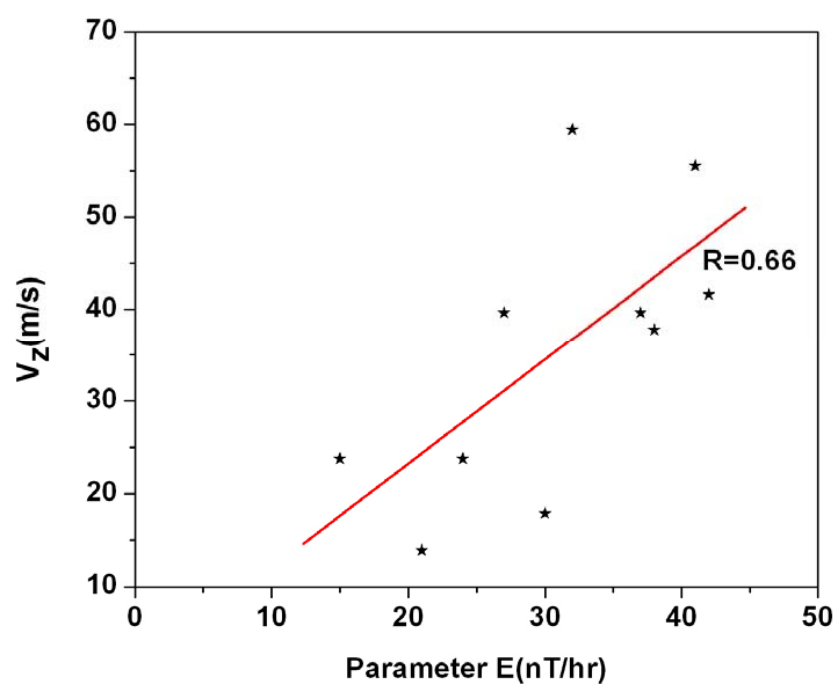

Fig. 4a. Scatter plot of the parameter "E" versus $V_{z}$ for some international quiet days of each month during the year 2001 .

moderate and minimum years is presented. The main results of the present study are summarized as follows: 


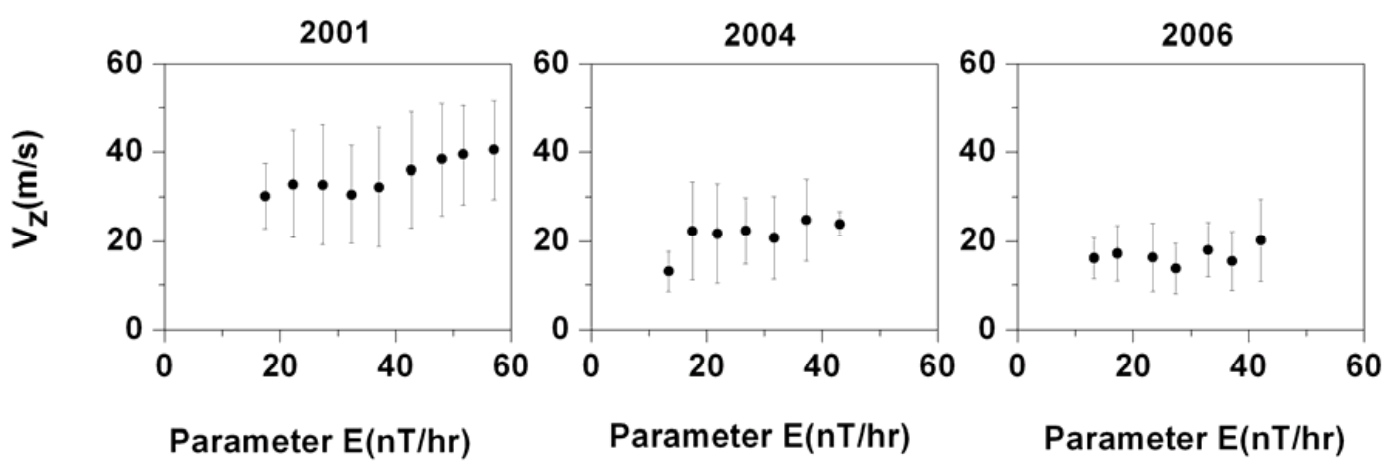

Fig. 4b. Plot of the average $V_{z}$, with the standard deviation, against the "parameter E", taken in intervals of $5 \mathrm{nT} / \mathrm{h}$, for the solar maximum, moderate and minimum years of 2001, 2004 and 2006.
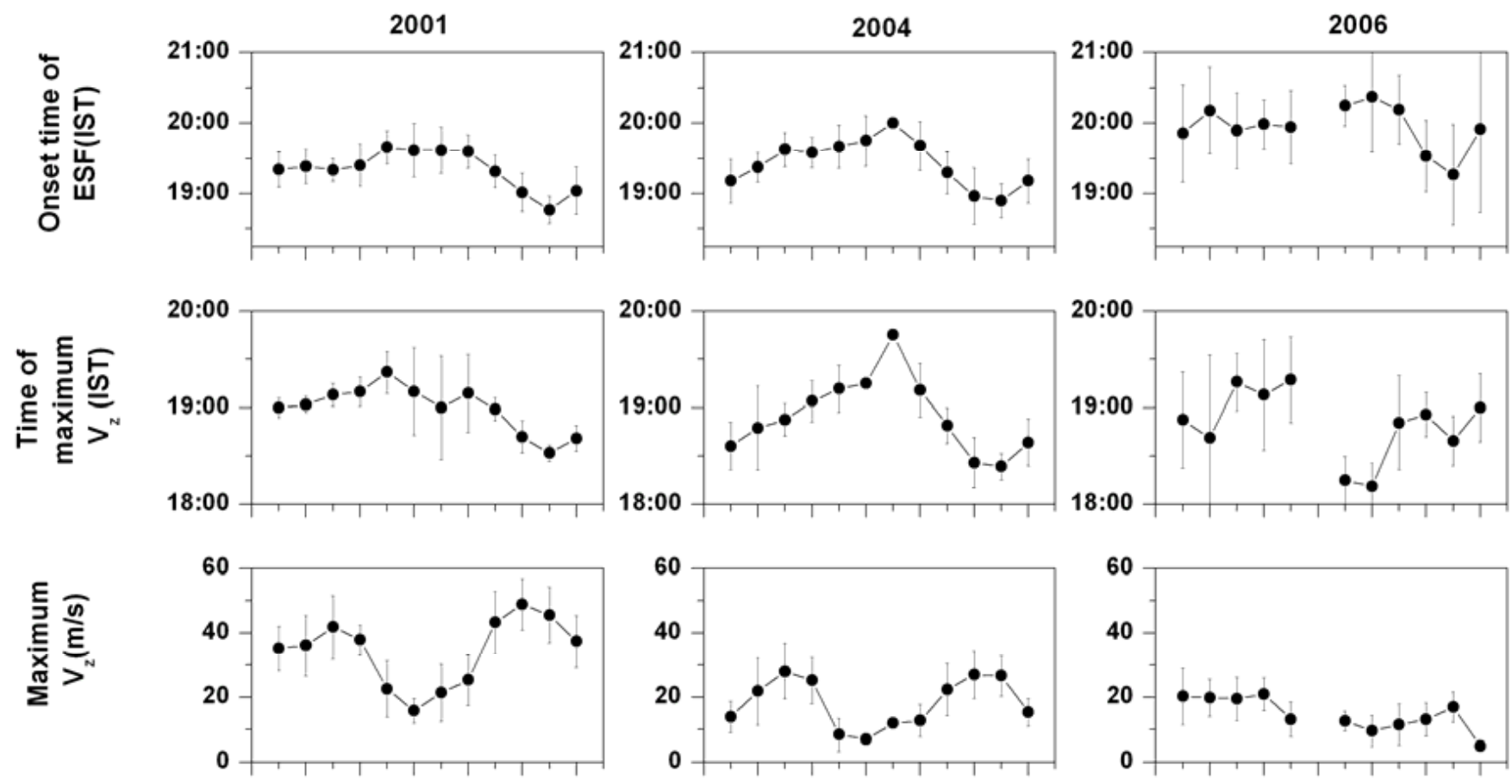

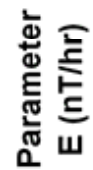
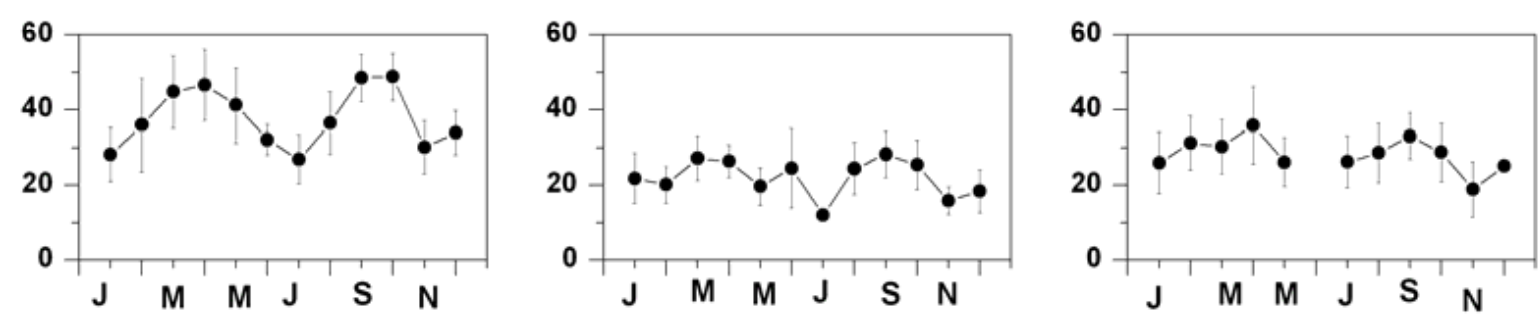

MONTHS

MONTHS

MONTHS

Fig. 5. Monthly mean variations of the "parameter E", maximum F-region vertical drift velocity $\left(V_{z}\right)$, its occurrence time and the onset time of ESF with the corresponding standard deviation for 2001, 2004 and 2006.

1. The detailed investigation has brought out some interesting results on the similarities in the monthly and seasonal variabilities of the various E- and F-region related parameters. These parameters show a reasonably good correspondence between them as well as with the seasonal patterns of ESF, as a function of solar activity also. 
2. These features are manifested with a very good similarity in the mean monthly and seasonal variabilities in the EEJ electric field related parameter "E" and the $\boldsymbol{E} \times \boldsymbol{B}$ drift velocity $\left(V_{z}\right)$ in the post sunset hours. These features can be useful for making a statistical inference of the post sunset F-region behavior from the daytime EEJ electric field characteristics which are directly obtained from the ground magnetic field variations. The results also enable us to make a quantitative estimation of the mean $V_{z}$ as a function of the magnitude of the parameter "E" on a monthly and seasonal basis.

The present study shows that the occurrence of ESF over different seasons is evidently correlated with the variations in the magnitude of the parameter "E" and $V_{z}$. The observed statistical correlation of these parameters with ESF events in the equinoctial and winter months of the solar minimum year and in all the months of the solar maximum and moderate year show that the ionosphere is lifted to higher altitudes where the gravitational drift term is dominant in the R-T instability growth rate, leading to the development of ESF, when the upward drift velocities are larger. Apart from the magnitude of $V_{z}$, the time of occurrence of the maximum value of $V_{z}$ is also observed to play a dominant role in the occurrence of ESF. Larger $V_{z}$ and its earlier occurrence time are observed to provide the favorable conditions for the earlier onset time of ESF. The earlier onset time of ESF during the equinoctial months and later onset time during the solstitial months thus follow from the seasonal patterns of the parameter "E" and $V_{z}$ variations.

It should be emphasized that the results of the present study are based on an analysis of three years of data-one year of solar maximum, one year of moderate activity and one year of solar minimum. It is to be expected that the relationship between parameter "E" and $V_{z}$ during the magnetically quiet days of other years should not deviate much from the presently arrived relationships. Hence the information on the parameter "E", as derived from the magnetometer measurements, seems to provide a simple method of establishing direct relationships the between parameter "E" and $V_{z}$ through the nature of their gross variabilities.

It should also be mentioned that a comprehensive understanding of the ESF phenomenon under varying seasonal and solar activity conditions is extremely important with our increased dependence on satellite based communications and geodesy. As already mentioned, ESF is an outcome of the $\mathrm{R}-\mathrm{T}$ instability in the equatorial ionosphere which in turn is controlled by both ionospheric and neutral atmospheric parameters like plasma density scale length $(L)$, ion-neutral collision frequency $\left(v_{i n}\right)$ and neutral winds in addition to the main driving factor viz: the gravity $(g)$. The generalized expression for the local growth rate of the R-T instability is given by the equation (Sekar and Raghavarao, 1987; Kelley, 1989),
$\gamma=\frac{1}{L}\left[\frac{g}{v_{i n}}+\frac{E_{X}}{B}+W_{x}\left(\frac{\nu_{i n}}{\Omega_{i}}\right)-W_{z}\right]$

where $W_{x}$ and $W_{z}$ are the zonal and vertical winds respectively, $E_{X}$ is the zonal electric field in the F-region, $B$ is the geomagnetic field and $\Omega_{i}$ is the ion gyro- frequency.

As it is clear from the Eq. (1), the growth rate depends mainly on $L$ and $v_{i n}$. At lower heights, the growth rate of the instability would decrease due to increased $v_{i n}$ and $L$. This along with the reduced zonal electric field during the solar minimum period would result in a low occurrence rate of ESF. During the solar maximum period, the comparatively larger value of the electric field would lift the F-layer to high enough altitudes (lower $v_{i n}$ and $L$ ), where the conditions are more favourable for the triggering of the R-T instability. The larger percentage occurrence of ESF during solar maximum period directly follows from these favourable conditions.

Acknowledgements. This work was supported by Department of Space, Government of India. One of the authors, V. Sreeja, gratefully acknowledges the financial assistance provided by the Indian Space Research Organization through Research Fellowship. The authors thank the Indian Institute of Geomagnetism (IIG), Mumbai, India for providing the magnetic field values.

Topical Editor M. Pinnock thanks H. Chandra and another anonymous referee for their help in evaluating this paper.

\section{References}

Aarons, J.: The longitudinal morphology of Equatorial F-layer irregularities relevant to their occurrence, Space Sci. Rev., 63, 209-243, 1993.

Abdu, M. A., Ramkumar, T. K., Batista, I. S., Brum, C. G. M., Takahasi, H., Reinisch, B. W., and Sobral, J. H. A.: Planetary wave signatures in the equatorial atmosphere-ionosphere system, and mesosphere- E- and F-region coupling, J. Atmos. Terr. Phys., 68, 509-522, 2006.

Abdu, M. A., Sobral, J. H. A., and Batista, I. S.: Equatorial spreadF statistics: some problems relevant to ESF description in the IRI scheme, Adv. Space Res., 25(1), 113-124, 2000.

Alex, S., Koparker, P. V., and Rastogi, R. G.: Spread F and ionization anomaly belt, J. Atmos. Terr. Phys., 51, 371-379, 1989.

Anderson, D., Anghel, A., Yumoto, K., Ishitsuka, M., and Kudeki, E.: Estimating daytime vertical ExB drift velocities in the equatorial F-region using ground-based magnetometer observations, Geophys. Res. Lett., 29, 1596, doi:10.1029/2001GL014562, 2002.

Basu, S., Kudeki, E., Basu, Su., Weber, E. J., Valladares, C. E., Sheehan, R., Meriwether, J. W., Kuenzler, H., Bishop, G. J., and Biondi, M. A.: Scintillations, Plasma drifts, and neutral winds in the equatorial ionosphere after sunset, J. Geophys. Res., 101, 26795-26809, 1996.

Batista, I. S., Abdu, M. A., and Bittencourt, J. A.: Equatorial F region vertical plasma drifts: seasonal and longitudinal asymmetries in the American sector, J. Geophys. Res., 91, 12055-12064, 1986.

Bittencourt, J. A. and Abdu, M. A.: A theoretical comparison between apparent and real ionization drift velocities in the equatorial F-region, J. Geophys. Res., 86, 2451-2454, 1981. 
Chandra, H. and Rastogi, R. G.: Solar cycle and seasonal variation of spread F near the magnetic equator, J. Atmos. Terr. Phys., 32, 439-443, 1970.

Crain, D. J., Heelis, R. A., and Bailey, G. J.: Effects of electrical coupling on equatorial ionosphere plasma motions: When is the F region a dominant driver in the low-latitude dynamics?, J. Geophys. Res., 98, 6033-6037, 1993.

Devasia, C. V., Jyoti, N., Vishwanathan, K. S., Subbarao, K. S., Tiwari, D., and Sridhran, R.: On the plausible linkage of thermospheric meridional winds with equatorial spread F, J. Atmos. Solar Terr. Phys., 64, 1-12, 2002.

Devasia, C. V., Sreeja, V., and Ravindran, S.: Solar cycle dependent characteristics of the equatorial blanketing $E_{S}$ layers and associated irregularities, Ann. Geophys., 24, 2931-2947, 2006, http://www.ann-geophys.net/24/2931/2006/.

Dunford, E.: The relationship between the ionospheric equatorial anomaly and the E-region current system, J. Atmos. Solar Terr. Phys., 29, 1489-1498, 1967.

Eccles, J. V.: A modeling investigation of the evening pre-reversal enhancement of the zonal electric field in the equatorial ionosphere, J. Geophys. Res., 103, 26709-26719, 1998.

Farley, D. T., Bonelli, E., Fejer, B. G., and Larsen, M. F.: The prereversal enhancement of the zonal electric field in the equatorial ionosphere, J. Geophys. Res., 91, 13723-13728, 1986.

Fejer, B. G., Scherliess, L., and de Paula, E. R.: Effects of the vertical plasma drift velocity on the generation and evolution of equatorial spread F, J. Geophys. Res., 104, 19854-19869, 1999.

Fejer, B. G.: Low latitude electrodynamic plasma drifts: A review, J. Atmos. Terr. Phys., 53, 677-693, 1991.

Fejer, B. G. and Kelley, M. C.: Ionospheric irregularities, Rev. Geophys., 18, 401-454, 1980.

Haerendel, G. and Eccles, J. V.: The role of the equatorial electrojet in the evening ionosphere, J. Geophys. Res., 97, 1181-1197, 1992.

Hysell, D. L. and Burcham, J.: Long term studies of equatorial spread F using the JULIA radar at Jicamarca, J. Atmos. Solar Terr. Phys., 64, 1531-1543, 2002.

Hysell, D. L.: An overview and synthesis of plasma irregularities in equatorial spread F, J. Atmos. Solar Terr. Phys., 62, 1037-1056, 2000 .

Jayachandran, P. T., Sri Ram, P., Somayajulu, V. V., and Rama Rao, P. V. S.: Effect of equatorial ionization anomaly on the occurrence of spread-F, Ann. Geophys., 15, 255-262, 1997, http://www.ann-geophys.net/15/255/1997/.

Kelley, M. C.: The Earth's Ionosphere, Academic Press, San Diego, 75-125, 1989.

Kelley, M. C., Ilma, R. R., and Crowley, G.: On the origin of prereversal enhancement of the zonal equatorial electric field, Ann. Geophys., 27, 2053-2056, 2009, http://www.ann-geophys.net/27/2053/2009/.

Krishna Murthy, B., Hari, S. S., and Somayajulu, V. V.: Nighttime equatorial thermospheric meridional winds from ionospheric h'F data, J. Geophys. Res., 95(A4), 4307-4310, 1990.

Kudeki, E., Bhattacharyya, S., and Woodman, R. F.: A new approach in incoherent scatter $F$ region ExB drift measurements at Jicamarca, J. Geophys. Res., 104, 28145-28162, 1999.

Liu, L., Luan, X., Wan, W., Lei, J., and Ning, B.: Solar activity variations of equivalent winds derived from global ionosonde data, $\mathrm{J}$. Geophys. Res., 109, A12305, doi:10.1029/2004JA010574, 2004.
Maruyama, T.: A diagnostic model for equatorial spread F 1. Model description and application to electric fields and neutral wind effects, J. Geophys. Res., 93, 14611-14622, 1988.

Maruyama, T. and Mattura, N.: Longitudinal variability of annual changes in activity of equatorial spread $\mathrm{F}$ and plasma bubbles, J. Geophys. Res., 89, 10903-10912, 1984.

Maynard, N. C., Aggson, T. L., Herrero, F. A., Liebrecht, M. C., and Sabu, J. L.: Average equatorial zonal and vertical ion drifts determined from San Marco D electric field measurements, J. Geophys. Res., 100, 17465-17479, 1995.

Mendillo, M., Meriwether, J., and Biondi, M.: Testing the thermospheric neutral wind suppression mechanism for day-to-day variability of equatorial spread F, J. Geophys. Res., 106, 3655-3663, 2001.

Raghavarao, R., Nageswararao, M., Sastri, J. H., Vyas, G. D., and Sriramarao, M.: Role of equatorial ionization anomaly in the initiation of equatorial spread F, J. Geophys. Res., 93, 5959-5964, 1988.

Raghavarao, R., Sharma, P., and Sivaraman, M. R.: Correlation of ionization anomaly with the intensity of the electrojet, Space Res., 18, 277-280, 1978.

Rastogi, R. G. and Rajaram, G.: Electrojet effects on the equatorial $F$ region during magnetically quiet and disturbed days, Ind. J Pure Appl. Phys., 9, 531-536, 1971.

Rishbeth, H.: The F-region dynamo, J. Atmos. Terr. Phys., 43, $387-$ 392, 1981.

Rush, C. M. and Richmond, A. D.: The relationship between the structure of the equatorial anomaly and the strength of the equatorial electrojet, J. Atmos. Terr. Phys., 35, 1171-1180, 1973.

Sastri, J. H.: Longitudinal dependence of equatorial F region vertical plasma drifts in the dusk sector, J. Geophys. Res., 101, 24452452, 1995.

Sastri, J. H.: Equatorial anomaly in F-region-A review, Indian J. Radio Space Phys., 19, 225-240, 1990.

Scherliess, L. and Fejer, B. G.: Radar and satellite global equatorial F region vertical drift model, J. Geophys. Res., 104, 6829-6842, 1999.

Sekar, R. and Raghavarao, R.: Role of vertical winds on the Rayleigh-Taylor instabilities of the night time equatorial ionosphere, J. Atmos. Terr. Phys., 49, 981-985, 1987.

Sridharan, R., Raju, D. P., Raghavarao, R. and Ramarao, P. V. S.: Precursor to equatorial spread-F in OI $630.0 \mathrm{~nm}$ dayglow, Geophys. Res. Lett., 21, 2797-2800, 1994.

Sultan, P.: Linear theory and modeling of the Rayleigh-Taylor instability leading to the occurrence of equatorial spread F, J. Geophys. Res., 101, 26875-26891, 1996.

Thampi, S. V., Sudha Ravindran, Tarun Kumar Pant, Devasia, C. V., Sreelatha, P., and Sridharan, R.: Deterministic prediction of postsunset ESF based on the strength and asymmetry of EIA from ground based TEC measurements: Preliminary results, Geophys. Res. Lett., 33, L13103, doi:10.1029/2006GL026376, 2006.

Vyas, G. D. and Chandra, H.: Ionospheric zonal drift reversal and equatorial spread F, Ann. Geophys., 9, 299-303, 1991.

Whalen, J. A.: Dependence of equatorial bubbles and bottomside Spread F on season, magnetic activity, and EXB drift velocity during solar maximum, J. Geophys. Res., 107(A2), 1024, doi:10.1029/2001JA000039, 2002.

Woodman, R. F. and LaHoz, C.: Radar observations of F region equatorial irregularities, J. Geophys. Res., 81, 5447-5466, 1976. 